and cardiopulmonary bypass was established. Ventilation was discontinued, and 2-cm skin incision was made at the 4th intercostal space for assisted window. Then 3 other small skin incisions were made to facilitate insertion of the endoscope and robotic arm. The pericardium was incised to expose the ascending aorta and right side of the heart. The ascending aorta was clamped, and antegrade cardioplegia was delivered from the ascending aorta. The right atrium was incised, and typical primum type ASD was observed. ASD closure with a biologic patch was performed. Cardiopulmonary bypass was tapered and stopped, and the heart started beating by itself. Left-sided single-lung ventilation was restarted. The tidal volume suddenly decreased, and strong positive-pressure ventilation was performed for a few seconds. At that time, sudden short ventricular tachycardia was noted. Moreover, the patient's blood pressure decreased from $120 \mathrm{~mm} \mathrm{Hg}$ to $85 \mathrm{~mm} \mathrm{Hg}$, and his central venous pressure increased from $5 \mathrm{~mm} \mathrm{Hg}$ to $12 \mathrm{~mm} \mathrm{Hg}$.

Transesophageal echocardiography revealed twisted atrial septum. Cardiac herniation was observed directly by endoscope (Video 1). The patient was maintained on durable ventilation, but his hemodynamic condition was unchanged. The left bronchus was blocked, and right-sided single ventilation was started after rotation of the patient's body to the left. The patient's hemodynamic condition improved, and the twisted atrial septum returned to the right position. The patient's hemodynamic condition was stable, and he was discharged 2 days after the operation.

\section{DISCUSSION}

Here we report a rare case of intraoperative cardiac herniation. Our patient had herniation develop as a result of strong positive ventilation to the left lung. Cardiac herniation during a cardiac operation is extremely rare; however, surgeons should be careful while adopting a right thoracic approach for cardiac operation. ${ }^{1}$ When performing robotassisted operations, surgeons work through a small window; this hinders the detection of unpredictable intraoperative adverse events. Intraoperative transesophageal echocardiography provided a lot of information in our case, and to our knowledge, ours are the first echocardiographic images showing intraoperative cardiac herniation during a robotassisted cardiac operation.

\section{Reference}

1. Speggiorin S, Padalino MA, Vida VL, Bonato R, Stellin G. Cardiac herniation after minimally invasive cardiac surgery: an unusual potentially lethal complication. Circulation. 2009;120:2509-10.

\title{
Pentacuspid aortic valve causing severe aortic regurgitation
}

\author{
Hidehito Kuroki, MD, Kazunobu Hirooka, MD, and Masahiro Ohnuki, MD, Ibaraki, Japan
}

Aortic valve dysfunction in relatively young adults may indicate congenital valve malformation. There have been occasional reports of anomalous monocuspid, bicuspid, and quadricuspid valves.

The incidence of bicuspid valves is $2 \%$ in the general population, and the incidence of quadricuspid valves is far less common, at approximately $0.003 \%$ to $0.013 \%{ }^{1}$ Even with technologic progress in image diagnosis, pentacuspid valves have been rarely described.

We report a case of a pentacuspid aortic valve consisting of normal left and right coronary cusps with 3 small cusps divided by well-developed commissures.

\footnotetext{
From the Department of Cardiovascular Surgery, Tsuchiura Kyodo General Hospital, Ibaraki, Japan

Disclosures: Authors have nothing to disclose with regard to commercial support.

Received for publication Oct 8, 2011; accepted for publication Oct 25, 2011; available ahead of print Nov 21, 2011.

Address for reprints: Hidehito Kuroki, MD, Manabe Shinmachi 11-7, Tsuchiura City, Ibaraki, 300-0053 Japan (E-mail: kurokihidehito@yahoo.co.jp).

J Thorac Cardiovasc Surg 2012;143:e11-2

$0022-5223 / \$ 36.00$

Copyright (c) 2012 by The American Association for Thoracic Surgery

doi:10.1016/j.jtcvs.2011.10.069
}

\section{CLINICAL SUMMARY}

A 46-year-old man presented with chest pain on exertion and frequent premature ventricular contractions on electrocardiography. Transthoracic echocardiography demonstrated severe aortic regurgitation with malformed leaflets and a moderately dilated left ventricle. Transesophageal echocardiography revealed aortic regurgitation due to 5 leaflets. Cardiac catheterization showed normal coronary arteries. The ejection fraction of the left ventricle was $57 \%$. Virtual intraaortic endoscopy by multidetector-row computed tomography confirmed the aortic valve to consist of 2 relatively large leaflets and 3 small leaflets (Figure 1). Premature ventricular contractions were of the monofocal type, originating from the left ventricular septum, around which the aortic regurgitant jet was exposed.

After median sternotomy, the pericardial reflection on the right side was found to shift anteriorly at the sulcus terminalis. Cardiopulmonary bypass was established by cannulation of the ascending aorta and right atrium. After oblique aortotomy, the aortic valve showed 5 clearly divided cusps. The left and right coronary cusps were relatively large, with each accompanied by its own coronary ostium at normal 


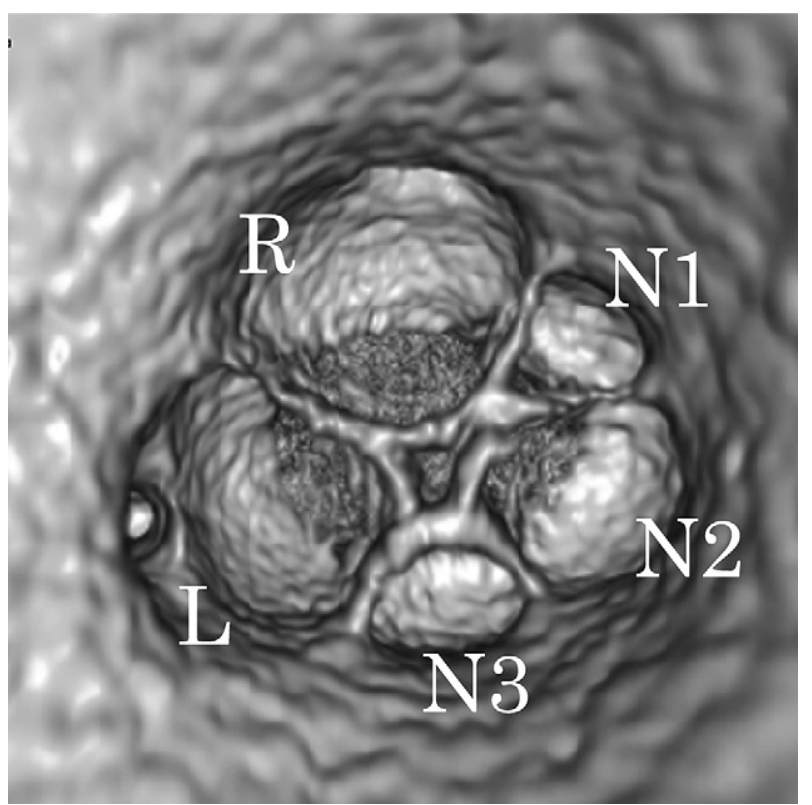

FIGURE 1. Virtual intraaortic endoscopy by multidetector computed tomography: The aortic valve consisted of 2 relatively large leaflets and 3 small leaflets. $R$, Right coronary cusp; $L$, Left coronary cusp; N1-3, Noncoronary cusp.

height (Figure 2). The 3 small divided cusps appear to have originated from the noncoronary cusp. After resection, a 22mm ATS AP360 (ATS Medical Inc, Minneapolis, Minn) was positioned intra-annularly. Histology revealed all cusps to show markedly myxomatous degeneration but with no indication of chronic inflammation or infection.

The patient's postoperative course was uneventful; however, the ventricular arrhythmia persisted. At the 7-month follow-up, the patient was still taking antiarrhythmic drugs.

\section{DISCUSSION}

Pentacuspid valve is a rare cardiac malformation. To the best of our knowledge, only 6 cases have been reported since Simonds ${ }^{2}$ described the first case in 1923. Four patients underwent valve replacement ${ }^{3-5}$; diagnosis was made by autopsy in 1 patient and by echocardiography in 1 patient. In 2 surgical cases, the valve configuration was stated to be clearly different in each. Bogers and colleagues $^{3}$ reported the right coronary cusp to be divided into 3, with a large left and a noncoronary cusp. Kamata and colleagues ${ }^{4}$ reported both right and noncoronary cusps to be equally divided into 2 segments, with a relatively normal-sized left coronary cusp. In the present case, the noncoronary cusp was divided into 3 small cusps with a relatively normal left and right coronary cusp.

Echocardiography demonstrated that the 3 small noncoronary cusps were so hypoplastic that they did not reach the center of the aortic valve opening. We do not know when the patient began to show aortic valve incompetence, but it



FIGURE 2. Operative view showing the pentacuspid aortic valve.

was concluded that the supernumerary cusps had not grown enough to achieve good coaptation with the other aortic cusps. The cause of anomalous valve formation has not been well explained, even for quadricuspid valves, which are more common than pentacuspid valves.

Embryologic extrapolation offers 3 possible critical phases when supernumerary cusped aortic valves can be formed. (1) Supernumerary prevalvular pads in the truncus evolve into supernumerary aortic cusps. (2) A truncus with a normal number of prevalvular pads is abnormally divided between the aorta and the pulmonary artery. (3) After normal separation of the great arteries, the prevalvular pads develop abnormally.

\section{CONCLUSIONS}

Because excessive valve division can be found in a noncoronary cusp, we suggest that it is possible for supernumerary prevalvular pads to emerge and develop into a multicuspid valve in little relation to any abnormal dividing pattern of the truncus arteriosus.

\section{References}

1. Janssens U, Klues HG, Hanrath P. Congenital quadricuspid aortic valve anomaly associated with hypertrophic non-obstructive cardiomyopathy: a case report and review of the literature. Heart. 1997;78:83-7.

2. Simonds JP. Congenital malformation of aortic and pulmonary valves. Am J Med Sci. 1923;166:584-95.

3. Bogers AJJC, Aytug Z, Hendriks FFA, Huysmans HA. Quinticuspid aortic valve causing aortic valve incompetence and stenosis. Thorax. 1982;37:542-3.

4. Kamata S, Sakagoshi N, Ohata T, Sasako Y. Successful surgical treatment of pentacuspid aortic valve with severe aortic regurgitation. Jpn J Cardiovasc Surg. 2008;37:53-5.

5. Wang S, Meng X, Zhang H, Wang J, Han J. Pentacuspid aortic valve with severe aortic regurgitation. Ann Thorac Surg. 2010;89:2034-6. 